\title{
Ion Beam Characterization of a NEXT Multi-Thruster Array Plume
}

Eric J. Pencil, John E. Foster, Michael J. Patterson, Esther M. Diaz,

Jonathan L. Van Noord, and Heather K. McEwen

Glenn Research Center, Cleveland, Ohio 


\section{NASA STI Program . . . in Profile}

Since its founding, NASA has been dedicated to the advancement of aeronautics and space science. The NASA Scientific and Technical Information (STI) program plays a key part in helping NASA maintain this important role.

The NASA STI Program operates under the auspices of the Agency Chief Information Officer. It collects, organizes, provides for archiving, and disseminates NASA's STI. The NASA STI program provides access to the NASA Aeronautics and Space Database and its public interface, the NASA Technical Reports Server, thus providing one of the largest collections of aeronautical and space science STI in the world. Results are published in both non-NASA channels and by NASA in the NASA STI Report Series, which includes the following report types:

- TECHNICAL PUBLICATION. Reports of completed research or a major significant phase of research that present the results of NASA programs and include extensive data or theoretical analysis. Includes compilations of significant scientific and technical data and information deemed to be of continuing reference value. NASA counterpart of peer-reviewed formal professional papers but has less stringent limitations on manuscript length and extent of graphic presentations.

- TECHNICAL MEMORANDUM. Scientific and technical findings that are preliminary or of specialized interest, e.g., quick release reports, working papers, and bibliographies that contain minimal annotation. Does not contain extensive analysis.

- CONTRACTOR REPORT. Scientific and technical findings by NASA-sponsored contractors and grantees.
- CONFERENCE PUBLICATION. Collected papers from scientific and technical conferences, symposia, seminars, or other meetings sponsored or cosponsored by NASA.

- SPECIAL PUBLICATION. Scientific, technical, or historical information from NASA programs, projects, and missions, often concerned with subjects having substantial public interest.

- TECHNICAL TRANSLATION. Englishlanguage translations of foreign scientific and technical material pertinent to NASA's mission.

Specialized services also include creating custom thesauri, building customized databases, organizing and publishing research results.

For more information about the NASA STI program, see the following:

- Access the NASA STI program home page at http://www.sti.nasa.gov

- E-mail your question via the Internet to help@sti.nasa.gov

- Fax your question to the NASA STI Help Desk at 301-621-0134

- Telephone the NASA STI Help Desk at 301-621-0390

- Write to:

NASA STI Help Desk

NASA Center for AeroSpace Information 7121 Standard Drive Hanover, MD 21076-1320 
NASA/TM-2006-214423

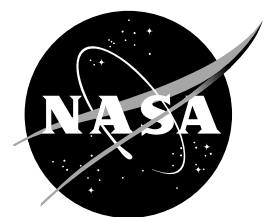

\section{Ion Beam Characterization of a NEXT Multi-Thruster Array Plume}

Eric J. Pencil, John E. Foster, Michael J. Patterson, Esther M. Diaz,

Jonathan L. Van Noord, and Heather K. McEwen

Glenn Research Center, Cleveland, Ohio

Prepared for the

42nd Joint Propulsion Conference and Exhibit

cosponsored by the AIAA, ASME, SAE, and ASEE

Sacramento, California, July 9-12, 2006

National Aeronautics and

Space Administration

Glenn Research Center

Cleveland, Ohio 44135 


\section{Acknowledgments}

The authors would like to acknowledge the support of the In-Space Propulsion program managed by the NASA Marshall Space Flight Center.

Level of Review: This material has been technically reviewed by technical management.

Available from

NASA Center for Aerospace Information

7121 Standard Drive

Hanover, MD 21076-1320
National Technical Information Service 5285 Port Royal Road Springfield, VA 22161

Available electronically at http://gltrs.grc.nasa.gov 


\title{
Ion Beam Characterization of a NEXT Multi-Thruster Array Plume
}

\author{
Eric J. Pencil, John E. Foster, Michael J. Patterson, Esther M. Diaz, \\ Jonathan L. Van Noord, and Heather K. McEwen \\ National Aeronautics and Space Administration \\ Glenn Research Center \\ Cleveland, Ohio 44135
}

\begin{abstract}
Three operational, engineering model, 7-kW ion thrusters and one instrumented, dormant thruster were installed in a cluster array in a large vacuum facility at NASA Glenn Research Center. A series of engineering demonstration tests were performed to evaluate the system performance impacts of operating various multiple-thruster configurations in an array. A suite of diagnostics was installed to investigate multiple-thruster operation impact on thruster performance and life, thermal interactions, and alternative system modes and architectures. The ion beam characterization included measuring ion current density profiles and ion energy distribution with Faraday probes and retarding potential analyzers, respectively. This report focuses on the ion beam characterization during single thruster operation, multiple thruster operation, various neutralizer configurations, and thruster gimbal articulation. Comparison of beam profiles collected during single and multiple thruster operation demonstrated the utility of superimposing single engine beam profiles to predict multi-thruster beam profiles. High energy ions were detected in the region $45^{\circ}$ off the thruster axis, independent of thruster power, number of operating thrusters, and facility background pressure, which indicated that the most probable ion energy was not effected by multiplethruster operation. There were no significant changes to the beam profiles collected during alternate thruster-neutralizer configurations, therefore supporting the viability of alternative system configuration options. Articulation of one thruster shifted its beam profile, whereas the beam profile of a stationary thruster nearby did not change, indicating there were no beam interactions which was consistent with the behavior of a collisionless beam expansion.
\end{abstract}

\section{Nomenclature}

$\begin{array}{ll}\text { DCA } & \text { Discharge Cathode Assembly } \\ \text { DCIU } & \text { Digital Control Interface Unit } \\ \text { EM } & \text { Engineering Model } \\ \text { FP } & \text { Full Power, corresponding to } \sim 6860 \mathrm{~W} \text { input power } \\ \text { GRC } & \text { Glenn Research Center } \\ \text { IP } & \text { Intermediate Power, corresponding to } \sim 2780 \mathrm{~W} \text { input power } \\ \mathrm{J}_{\mathrm{a}} & \text { Accelerator grid impingement current, mA } \\ \mathrm{J}_{\mathrm{b}} & \text { Beam current, A } \\ \text { LP } & \text { Low Power, corresponding to } \sim 1120 \mathrm{~W} \text { input power } \\ \mathrm{mN} & \text { milli-Newton } \\ \mathrm{M}_{\mathrm{n}} & \text { Neutralizer Flow Rate, sccm Xe } \\ \text { MTAT } & \text { Multi-Thruster Array Test } \\ \text { NCA } & \text { Neutralizer Cathode Assembly } \\ \text { NEXT } & \text { NASA's Evolutionary Xenon Thruster } \\ \text { PAT } & \text { Performance Assessment Test } \\ \text { P } & \text { Input power into thruster, W } \\ \text { PMS } & \text { Propellant Management System } \\ \text { PPU } & \text { Power Processing Unit }\end{array}$




$\begin{array}{ll}\mathrm{P}_{\text {true }} & \text { Facility pressure corrected for xenon, Torr } \\ \mathrm{RPA} & \text { Retarding Potential Analyzer } \\ \mathrm{V}_{\mathrm{a}} & \text { Acceleration voltage, } \mathrm{V} \\ \mathrm{V}_{\mathrm{b}} & \text { Beam voltage, } \mathrm{V} \\ \mathrm{V}_{\mathrm{g}} & \text { Coupling voltage (neutralizer common-to-facility ground), } \mathrm{V}\end{array}$

\section{Introduction}

The NASA Glenn Research Center is responsible for the development of NASA's Evolutionary Xenon Thruster (NEXT) ion propulsion system. The objective of the NEXT project is to advance next generation ion propulsion technology readiness. The NEXT system consists of a high-performance, 7-kW ion thruster; a lightweight, high-efficiency, 7-kW power processor unit (PPU); a highly flexible advanced xenon propellant management system (PMS); a lightweight engine gimbal; and key elements of a digital control interface unit (DCIU) including software algorithms (refs. 1 to 4). This design approach was selected to provide future NASA science missions with the greatest value in mission performance benefit at a low total development cost. Technology validation and mission analysis efforts, conducted in Phase 1 , indicated the NEXT propulsion system can provide the capabilities to achieve aggressive outer planetary science missions and that further development was warranted in Phase 2 (ref. 5).

A multi-thruster array test (MTAT) was beneficial to address thruster and gimbal-specific questions that drive the configuration of the ion propulsion system components as well as the configuration of the final multi-thruster system test to be executed at the completion of Phase 2. This MTAT utilized multiple engineering model (EM) NEXT ion thrusters as well as laboratory power consoles and laboratory propellant feed systems to operate multiple thrusters simultaneously. The engineering demonstration portion of MTAT focused on the characterization of performance and behavior of the individual thrusters and the array as affected by the simultaneous operation of multiple ion thrusters. The main focus of this characterization is a four-NEXT thruster array in a " $3+1$ " configuration, where three thrusters are operational and one thruster is dormant (a spare). The results of the engineering demonstration are reported in Reference 6 and address the following objectives:

- Document multi-thruster system performance and provide data to predict array lifetime;

- Assess performance and lifetime implications of multi-thruster operations on individual thrusters as a function of operating mode, gimbal angle, and array configuration;

- Assess thermal interactions;

- Document alternative system modes and architectures, including various neutralizer configurations; and

- Assess impact of multi-thruster operations on PPU and PMS subsystem performance.

The MTAT physics effort focuses on the characterization of the plasma environment generated by the simultaneous operation of multiple ion thrusters. The interaction of this plasma environment with the spacecraft and the thrusters themselves plays an important role in the determination of spacecraft configuration, acceptable array operating condition, and array lifetime. The purpose of the MTAT physics effort is to address the following objectives:

- Assess the effect of multi-thruster operation on ion thruster grid lifetime;

- Assess how spacecraft structures are affected by the plasma particles and potential fields due to multi-thruster operation including gimbaling;

- Assess how performance parameters such as neutralizer margin and plume divergence are affected by multi-thruster operation; and

- Assess how the dormant thruster is affected by the ambient plasma environment produced by the multi-thruster array. 
This paper documents the characterization of the ion beam produced by the MTAT using Faraday probes and a retarding potential analyzer. Specifically the ion beams are characterized during single- and multi-thruster operation to assess the degree of beam-beam plume interactions. The ion beams are characterized during various neutralizer configurations to investigate any unanticipated beam-neutralizer plume interactions during alternate neutralizer operation. Finally the ion beams are characterized during gimbal articulation to determine if significant beam-beam interactions exist. Significant changes to the thrust-generating ion beams during these test segments would indicate potential changes to the performance of the ion propulsion system due to operation in a multi-thruster array configuration. Companion papers document array local plasma (ref. 7), electron flowfield characteristics of the plume(ref. 8), and neutralizer coupling characteristics (ref. 9).

\section{Experimental Apparatus}

\section{A. Array Configuration}

The thruster array consisted of four NEXT EM ion thrusters (EM1, EM2, EM4, and EM5) all manufactured at NASA GRC. The configuration of the three active thrusters is as identified in table 1 with 'New' referring to pristine, previously untested hardware. The array's nominal configuration was a " $3+1$ " geometry, whose spacing and thruster locations were chosen based on a spacecraft design activity conducted for a Titan orbiter mission using a NEXT ion propulsion system (ref. 10); the baseline thruster spacing was $0.64 \mathrm{~m}$ center-to-center both vertically and horizontally [0.91 m center-to-center diagonally]. The NEXT array in this nominal configuration is shown in figures 1 and 2. For these tests EM2 functioned as the dormant (flight spare) thruster. Its optics were replaced with a collector gird and outfitted with plasma probes. Laboratory propellant feed systems and laboratory power consoles were used to operate the individual thrusters. Vacuum Facility 6 (VF6), a space simulation chamber at NASA GRC, was used for all array testing. VF6 was $7.6 \mathrm{~m}$ in diameter and $22.9 \mathrm{~m}$ long and was evacuated with 12 cryogenic pumps. The array assembly was installed into the facility such that the thrusters fired along the long-axis of the facility. Additional information about the thruster array and supporting equipment can be found in reference 6 .

TABLE 1.-CONFIGURATION OF ACTIVE EM THRUSTERS

\begin{tabular}{|l|l|l|l|}
\hline \multicolumn{1}{|c|}{ Component } & \multicolumn{1}{|c|}{ EM1 } & \multicolumn{1}{c|}{ EM4 } & \multicolumn{1}{c|}{ EM5 } \\
\hline DCA & New & New & New \\
\hline NCA & New & New & New \\
\hline Ion Optics [Beam dia.] & Pre-Operated $[40 \mathrm{~cm}]$ & Pre-Operated $[36 \mathrm{~cm}]$ & New $[40 \mathrm{~cm}]$ \\
\hline Discharge Chamber & Pre-Operated & New & New \\
\hline
\end{tabular}

\section{B. Planar Faraday Probes}

Circular, planar Faraday probes were implemented to characterize the ion density profile. The probes had a $1 \mathrm{~cm}^{2}$ circular collection area made from molybdenum, and were surrounded by a grounded guard ring. Six probes were mounted on a vertical probe rake which was in turn mounted onto a two-axis motorized motion control system for measuring the ion beam current densities. Figure 3 shows a schematic of the path of the planar probes relative to the thruster array. Table 2 details the vertical locations of probes 1-6 on the probe rake relative to the array centerline. Probe 2 traversed the centerlines of EM1 and EM2, whereas Probe 6 traversed the centerlines of EM4 and EM5. The positioning system swept the probes in the radial $\left(\mathrm{x}^{\prime}\right)$ and axial $\left(\mathrm{z}^{\prime}\right)$ directions downstream of the engine ion optics, with $1.5 \mathrm{~m}$ travel in each axis. Data were collected during the outbound segment of the sweep or the $+\mathrm{x}^{\prime}$ direction only. 


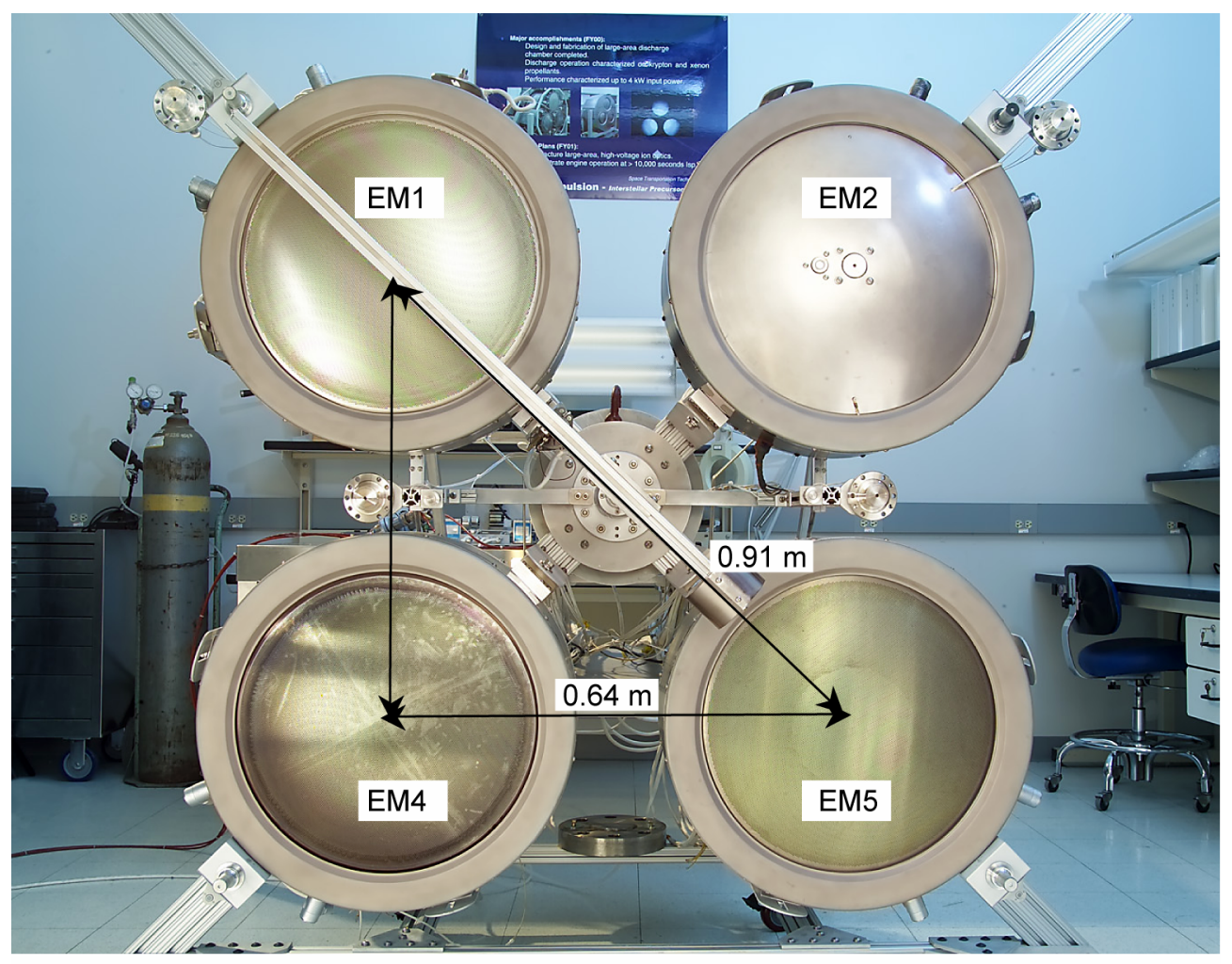

Figure 1.-" $3+1 "$ configuration NEXT multi-thruster array.

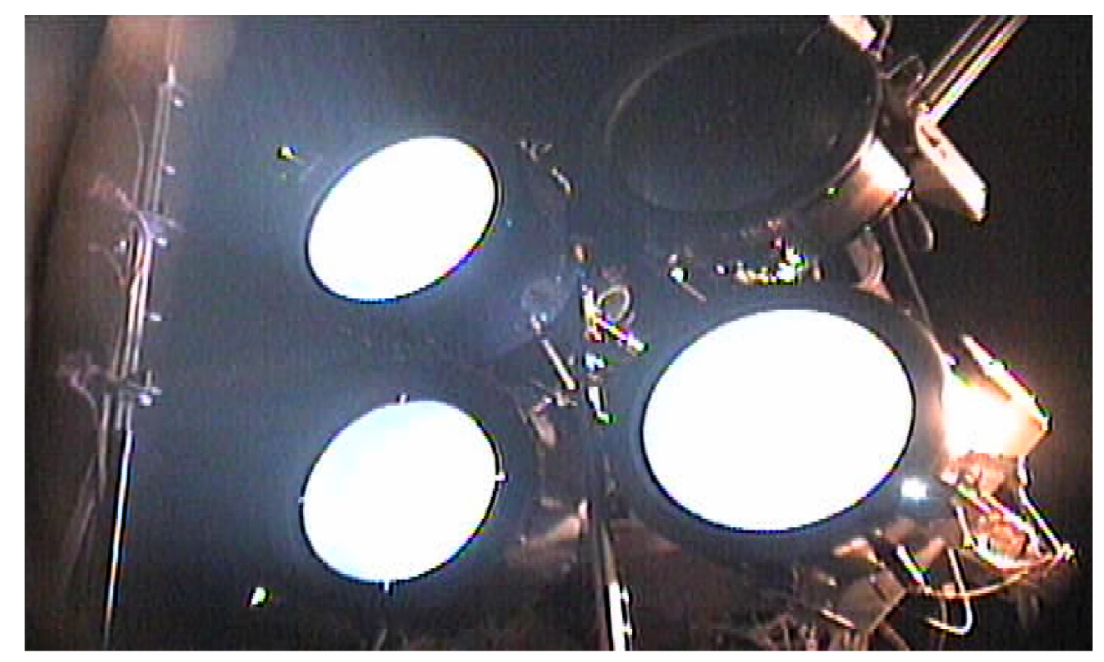

Figure 2.-"3+1" configuration NEXT multi-thruster array operating in Vacuum Facility 6 at NASA GRC. Faraday probe rake is visible on the left. 


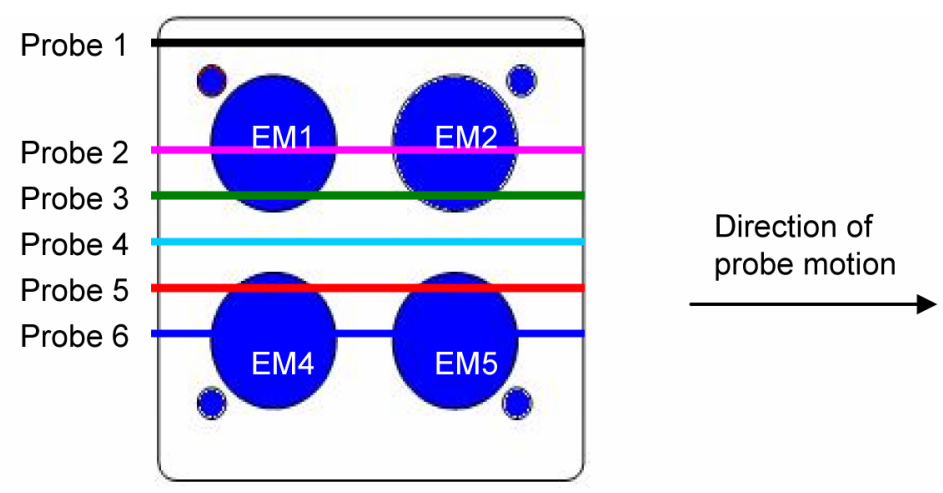

Figure 3.-Schematic of Faraday probe motion during data collection.

TABLE 2.-PLANAR FARADAY PROBE VERTICAL POSITIONS ALONG VERTICAL PROBE RAKE. POSITIVE DISTANCES DENOTE DISTANCE ABOVE ARRAY CENTERLINE. NEGATIVE DISTANCES DENOTE DISTANCE BELOW ARRAY CENTERLINE

\begin{tabular}{|c|l|}
\hline Probe Number & \multicolumn{1}{|c|}{ Probe Location } \\
\hline 1 & $721 \mathrm{~mm}$ \\
\hline 2 & $318 \mathrm{~mm}$ [aligned with centers of EM1 and EM2] \\
\hline 3 & $157 \mathrm{~mm}$ \\
\hline 4 & $0 \mathrm{~mm}$ [array centerline] \\
\hline 5 & $-158 \mathrm{~mm}$ \\
\hline 6 & $-317 \mathrm{~mm}$ [aligned with centers of EM4 and EM5] \\
\hline
\end{tabular}

\section{Off-Axis Retarding Potential Analyzer (RPA)}

The off-axis RPA, used to detect and determine the energy of the off-axis beam ions, was a commercially available, gridded Faraday cup. The entrance diameter was $5.0 \mathrm{~mm}$ while the physical diameter of the probe face was $28 \mathrm{~mm}$. The probe had three grids: a grounded entry grid, an ion-retarding grid, and an electron-repelling grid biased to $-27 \mathrm{~V}$. The collector was biased to $-32 \mathrm{~V}$. The RPA data were collected by ramping the ion retarding grid up to $2000 \mathrm{~V}$ and recording the voltage and collected current as measured by an electrometer. In all cases, the probe current signal dropped to zero amperes near the beam voltage, thereby making scans to appreciably higher voltages unnecessary. As the ion repelling grid was biased more positive, it repelled ions of increasing energy. This provided a currentvoltage (I-V) characteristic from which the most probable ion energy and the ion energy distribution could be obtained. The off-axis RPA was located $1 \mathrm{~m}$ axially downstream and $1 \mathrm{~m}$ radially from the centerline of EM1 ( $45^{\circ}$ from the thruster centerline). The off-axis RPA was vertically located at the same height as the centerline of EM1.

\section{Operating Conditions}

Table 3 lists the key thruster operating parameters of the thrusters during the test sequences discussed in this report. Reference 6 provides additional details about the experimental set up and instrumentation used to measure these parameters. 
TABLE 3.-THRUSTER OPERATING PARAMETERS DURING VARIOUS TEST SEGMENTS.

\begin{tabular}{|l|c|c|c|c|c|}
\hline \multicolumn{1}{|c|}{ Thruster Condition } & $\begin{array}{c}\mathbf{V}_{\mathbf{b}} \\
\mathbf{( V )}\end{array}$ & $\begin{array}{c}\mathbf{J}_{\mathbf{b}} \\
(\mathbf{A})\end{array}$ & $\begin{array}{c}\mathbf{V}_{\mathbf{a}} \\
(\mathbf{V})\end{array}$ & $\begin{array}{c}\mathbf{J}_{\mathbf{a}} \\
(\mathbf{m A})\end{array}$ & $\begin{array}{c}\mathbf{P}_{\text {true }} \\
\text { (torr) }\end{array}$ \\
\hline EM1@FP & 1790 & 3.52 & -211 & 12.6 & $1.2 \times 10^{-6}$ \\
\hline EM4@FP & 1788 & 3.52 & -210 & 13.6 & $1.2 \times 10^{-6}$ \\
\hline EM5@FP & 1788 & 3.52 & -210 & 13.7 & $1.1 \times 10^{-6}$ \\
\hline EM1 during (EM1+EM4+EM5)@FP & 1790 & 3.55 & -210 & 22.2 & $3.0 \times 10^{-6}$ \\
\hline EM4 during (EM1+EM4+EM5)@FP & 1789 & 3.53 & -210 & 23.5 & $3.0 \times 10^{-6}$ \\
\hline EM5 during (EM1+EM4+EM5)@FP & 1790 & 3.54 & -210 & 22.9 & $3.0 \times 10^{-6}$ \\
\hline EM1@IP & 1169 & 2.00 & -200 & 5.4 & $7.1 \times 10^{-7}$ \\
\hline EM1@LP & 671 & 1.21 & -115 & 3.6 & $4.6 \times 10^{-7}$ \\
\hline $\begin{array}{c}\text { EM1 during (EM1+EM5)@LP } \\
\text { with2 neutralizers }\end{array}$ & 670 & 1.20 & -115 & 3.6 & $8.2 \times 10^{-7}$ \\
\hline $\begin{array}{c}\text { EM5 during (EM1+EM5)@LP } \\
\text { with2 neutralizers }\end{array}$ & 670 & 1.20 & -115 & 3.7 & $8.2 \times 10^{-7}$ \\
\hline $\begin{array}{c}\text { EM1 during (EM1+EM5)@LP } \\
\text { with1 neutralizer }\end{array}$ & 669 & 1.20 & -115 & 3.7 & $7.5 \times 10^{-7}$ \\
\hline $\begin{array}{c}\text { EM5 during (EM1+EM5)@LP } \\
\text { with1 neutralizer }\end{array}$ & 669 & 1.20 & -115 & 3.7 & $7.5 \times 10^{-7}$ \\
\hline EM1 during (EM1+EM5)@FP & 1791 & 3.54 & -210 & 17.1 & $2.0 \times 10^{-6}$ \\
\hline EM5 during (EM1+EM5)@FP & 1789 & 3.52 & -210 & 17.9 & $2.0 \times 10^{-6}$ \\
\hline
\end{tabular}

\section{Results and Discussion}

\section{A. Single Thruster Operation-Ion Current Density Profiles}

Figure 4 shows the beam profiles collected by Probe 2 across the thruster centerline for EM1 at full power operation (EM1@FP), corresponding to $6860 \mathrm{~W}$ into the thruster. The peak current density collected at $\mathrm{z}^{\prime}=250 \mathrm{~mm}$ was $2.3 \mathrm{~mA} / \mathrm{cm}^{2}$, which was near the center of the thruster, located at $-320 \mathrm{~mm}$. The left hand side of the beam profile for EM1 was truncated due to the length of travel limitations of the motion control tables. The peak current dropped exponentially and the beam widened as the axial distance increased as expected. The beam profile was approximately symmetric about the centerline. By assuming axisymmetry it is possible to integrate the radial beam profile and compare the results to the beam current. Integration of the beam profile from the thruster centerline toward the array centerline, yielded a current which was 5 to 12 percent higher than the measured beam current. The discrepancy was consistent with the effect of charge exchange ions and background plasma which would likely add to the measured current density profile. The beam divergence half angle was calculated to be $24 \pm 1^{\circ}$, which is consistent with previous results obtained with this thruster design (ref. 11).

Figure 5 shows the beam profiles collected by Probe 6 across the thruster centerline for EM4 at full power operation (EM4@FP). The peak current density collected at $\mathrm{z}^{\prime}=250 \mathrm{~mm}$ was $2.3 \mathrm{~mA} / \mathrm{cm}^{2}$, which was near the center of the thruster, located at $-320 \mathrm{~mm}$. Although a slight azimuthal asymmetry was noted, the beam profile was approximately symmetric about the thruster centerline, since the current density radial profiles matched within 4 percent when comparing the right-hand and left-hand sides. The peak current density of the beam profile decreased as the axial distance increased. The beam profile widened as the axial distance increased. Integration of the beam profile for EM4 matched the beam current to within 5 to 12 percent. The beam divergence half angle was determined to be $25 \pm 1^{\circ}$. 


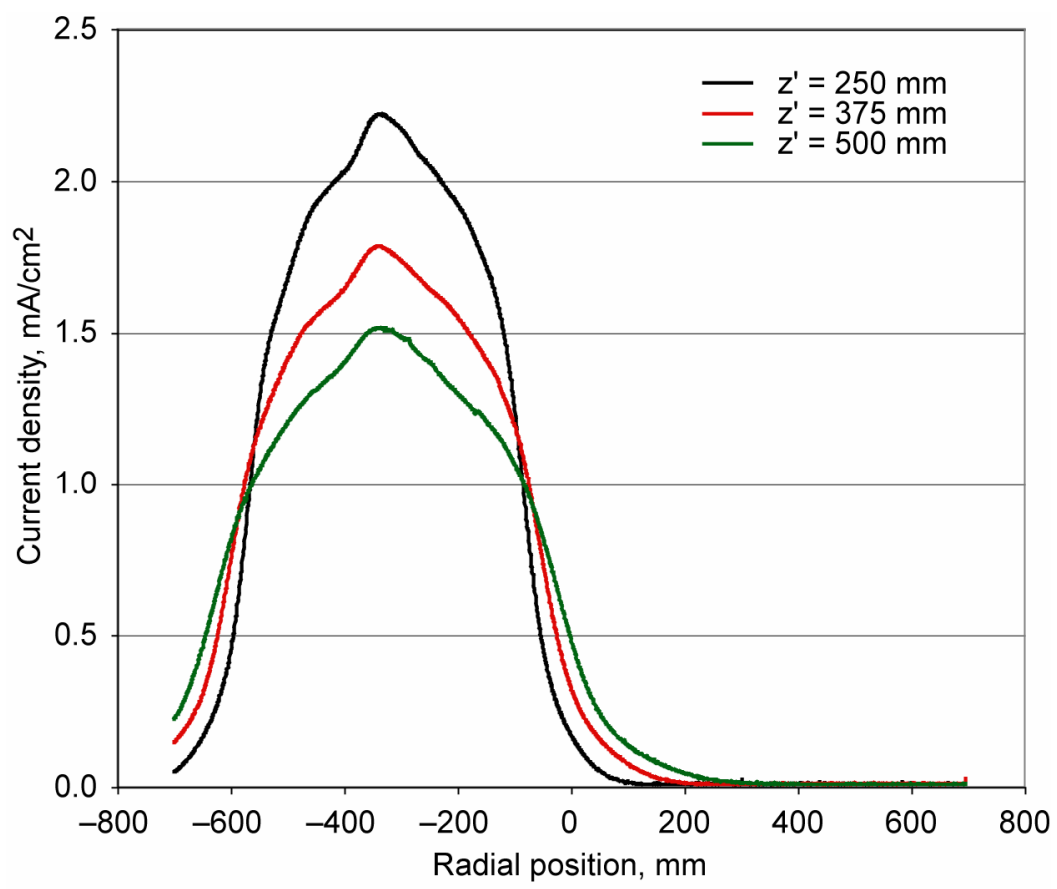

Figure 4.- Ion current density profiles for EM1 at full power.

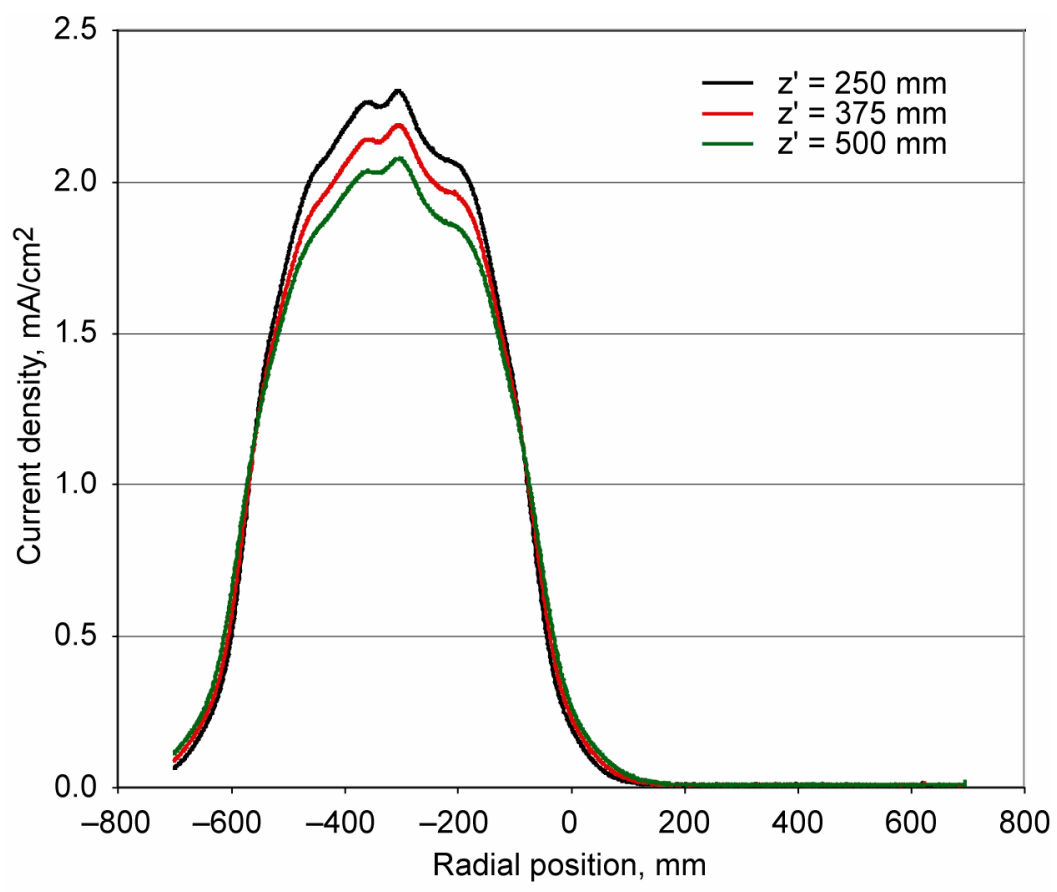

Figure 5.-- Ion current density profiles for EM4 at full power. 


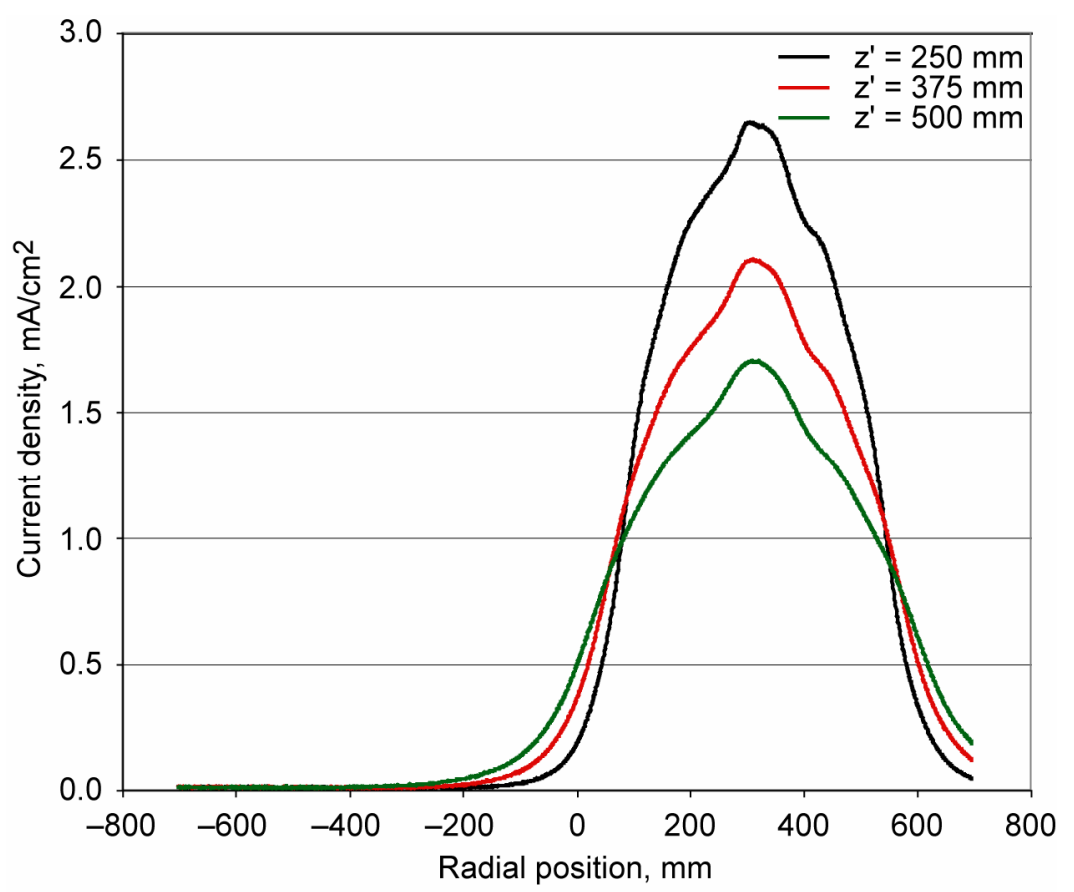

Figure 6.-Ion current density profiles for EM5 at full power.

The beam profiles collected by Probe 6 across the thruster centerline for EM5 at full power operation (EM5@FP) are shown in figure 6. The beam profile was approximately symmetric about the thruster center, located at $320 \mathrm{~mm}$. The right hand side of the beam profile for EM5 was truncated due to the size limitations of the motion control tables. Integration of the beam profile for EM5 matched the beam current to within 10 to 16 percent. The beam divergences half angle was determined to be $24 \pm 1^{\circ}$.

A comparison of the beam profiles for EM1, EM4 and EM5 collected at an axial distance of $250 \mathrm{~mm}$ is shown in figure 7. EM1 and EM4 profiles compare well despite the fact the EM4 optics were masked down to $36 \mathrm{~cm}$. The result was expected given the current density in the outer $2 \mathrm{~cm}$ was negligible (ref. 12). The beam profile of EM5 was more peaked when compared to the beam profiles of either EM1 or EM4. The difference in the EM5 beam profile as compared to the EM1 and EM4 beam profiles was attributed to small differences in the grid spacing measured during optics assembly. The smaller grid gap, associated with EM5 optics, would make the transparency higher along the thruster centerline resulting in higher current densities. It should be noted that although variations in the beam profiles existed from thruster to thruster, these differences were not significant enough to invalidate the MTAT test results.

\section{B. Single Thruster Operation-Off-axis Ion Energy Distribution}

Off-axis RPA data was collected for the various EM1 thruster power levels; Low Power (LP) or $1120 \mathrm{~W}$, Intermediate Power (IP) or $2780 \mathrm{~W}$ and Full Power (FP) or $6860 \mathrm{~W}$. The current-voltage (I-V) 
curves are shown in figure 8(a). The I-V curves were normalized by the peak current in each case. The theoretical RPA I-V curve for an ion beam would exhibit a step function behavior with discontinuities at the peak ion energies. The derivative of an RPA I-V curve at a given test condition provided the distribution of ion energies at that location, with the peaks located at the most probable ion energies. Given the RPA data was collected at discrete bias voltages with $20-\mathrm{V}$ intervals, the slope for each interval was calculated and plotted against the average bias voltage in that interval. Given that the entrance grid was grounded, data was not corrected for the voltage-to-ground potential $\left(\mathrm{V}_{\mathrm{g}}\right)$. Figure $8(\mathrm{~b})$ shows the derivative (i.e., slope of the I-V curve) for each thruster power level. The most probable ion energy matched the beam voltage in all cases. The most probable ion energy was found to be $690 \mathrm{eV}$ for LP, $1190 \mathrm{eV}$ for IP, and $1830 \mathrm{eV}$ for FP, whereas the beam voltage was 671, 1169, and $1790 \mathrm{~V}$ for LP, IP and $\mathrm{FP}$, respectively. The small discrepancy was attributed primarily to an uncertainty of $\pm 10 \mathrm{~V}$ associated with data collection at discrete bias voltages. The minor peaks between 100 and $200 \mathrm{~V}$ were due to noise in the signal associated with low ion densities noted during low power operation. The results clearly showed that high-energy ions were present at $45^{\circ}$ off the thruster axis at all operating conditions, which is important from a plume-spacecraft interaction perspective.

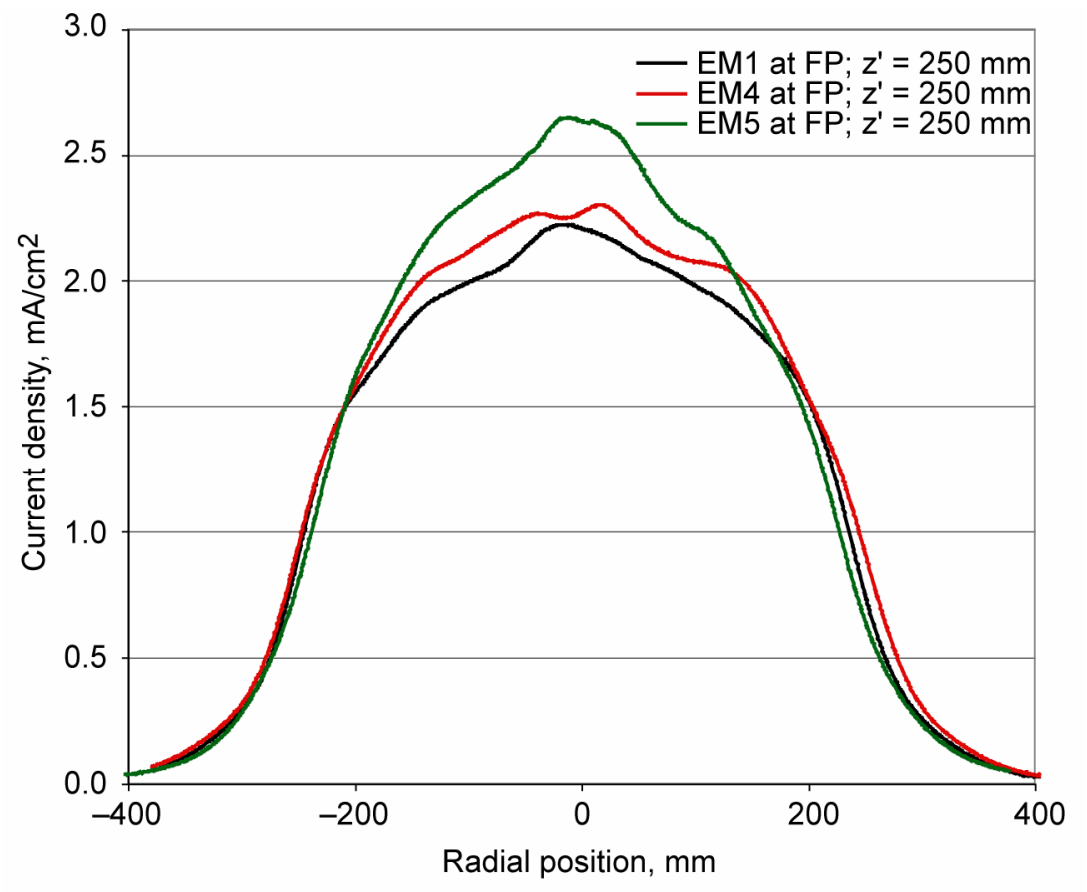

Figure 7.-Comparison of beam profiles for EM1, EM4, and EM5 at full power. 

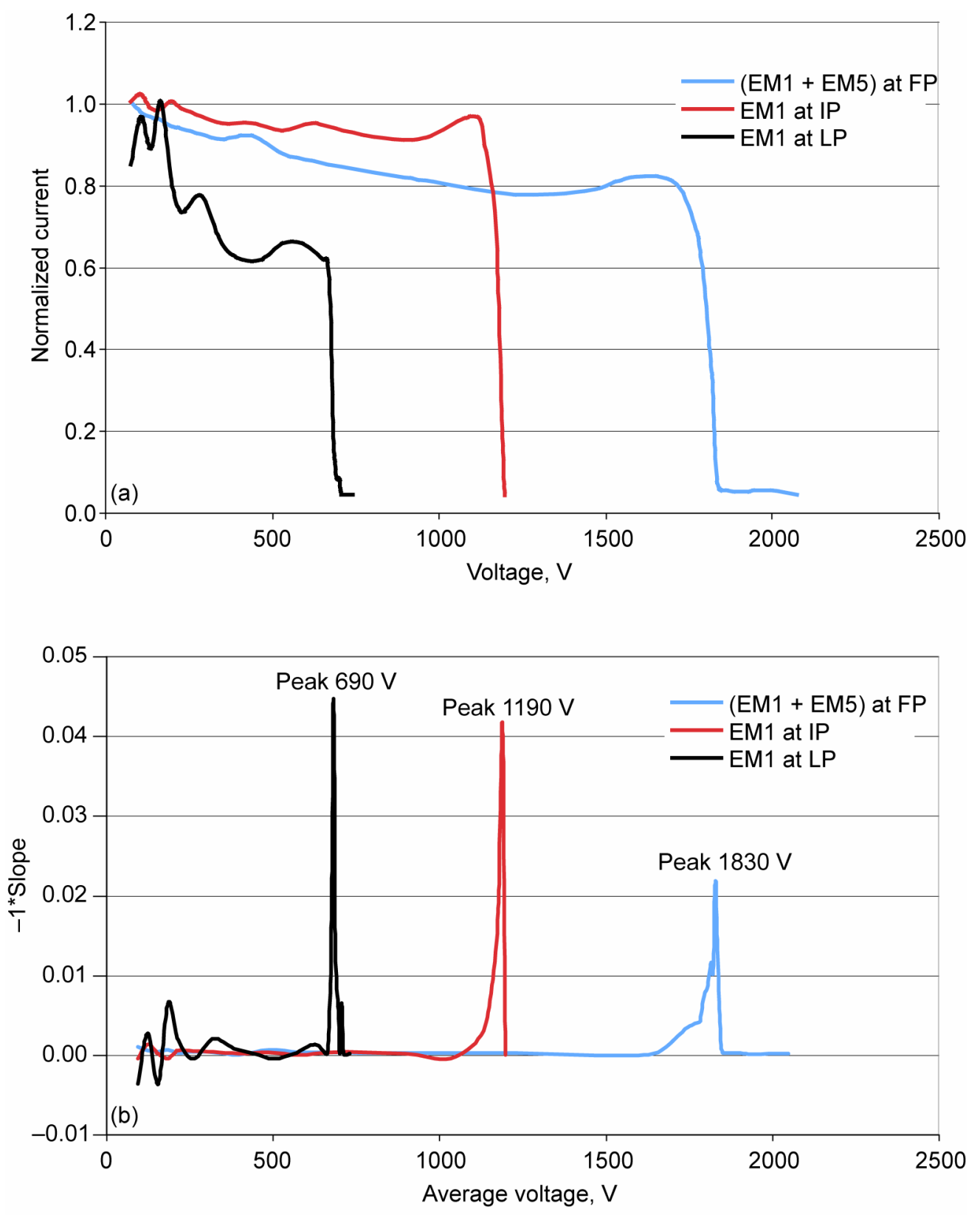

Figure 8.-(a) Normalized RPA collector current versus bias voltage for LP, IP, and FP operation of EM1. (b) lon energy distribution functions for LP, IP and FP operation of EM1 45 degrees off-axis. (The peaks corresponded to most probable ion energy.) 


\section{Multiple Thruster Operation-Ion Current Density Profiles}

\section{Ion Current Density Profiles}

Faraday probes were used to measure the ion density profiles during the simultaneous operation of multiple thrusters; EM1, EM4, and EM5. Both ion density profiles for both Probe 2 and Probe 6 are shown in figure 9. The ion current density measured by Probe 2 represented the beam profile of EM1 measured across the thruster centerline. The ion current density measured by Probe 6 represented the beam profiles of EM4 and EM5 measured along the centerline of both thrusters. Note that the overlap of the beams of EM4 and EM5 occurred along the array centerline as early as $250 \mathrm{~mm}$. The current density in the trough at the array centerline increased as axial distance to the thruster increased and was attributed to finite plume divergence.

To gain insight into the effect of multiple thruster operation on the primary beam characteristics, an investigation of the effect of the number of active thrusters on the current density profiles was completed. The current density profiles for single engine operation (EM1@FP, EM4@FP, and EM5@FP) were compared to current density profiles for multiple engine operation, (EM1+EM4+EM5)@FP. Figure 10 shows the comparison of the beam profiles collected during single engine and multiple engine operation at an axial distance of $z^{\prime}=250 \mathrm{~mm}$. The current density profiles collected by Probe 2 across the centerline of EM1 during single engine operation and multiple engine operation indicated there was only a minor difference between the two cases. Integration of the beam profiles in the two cases indicated the difference in beam currents was less than $0.2 \mathrm{~A}$ or 6 percent. The current density profiles collected by Probe 6 across the centerline of EM4 and EM5 during single engine operation and multiple engine

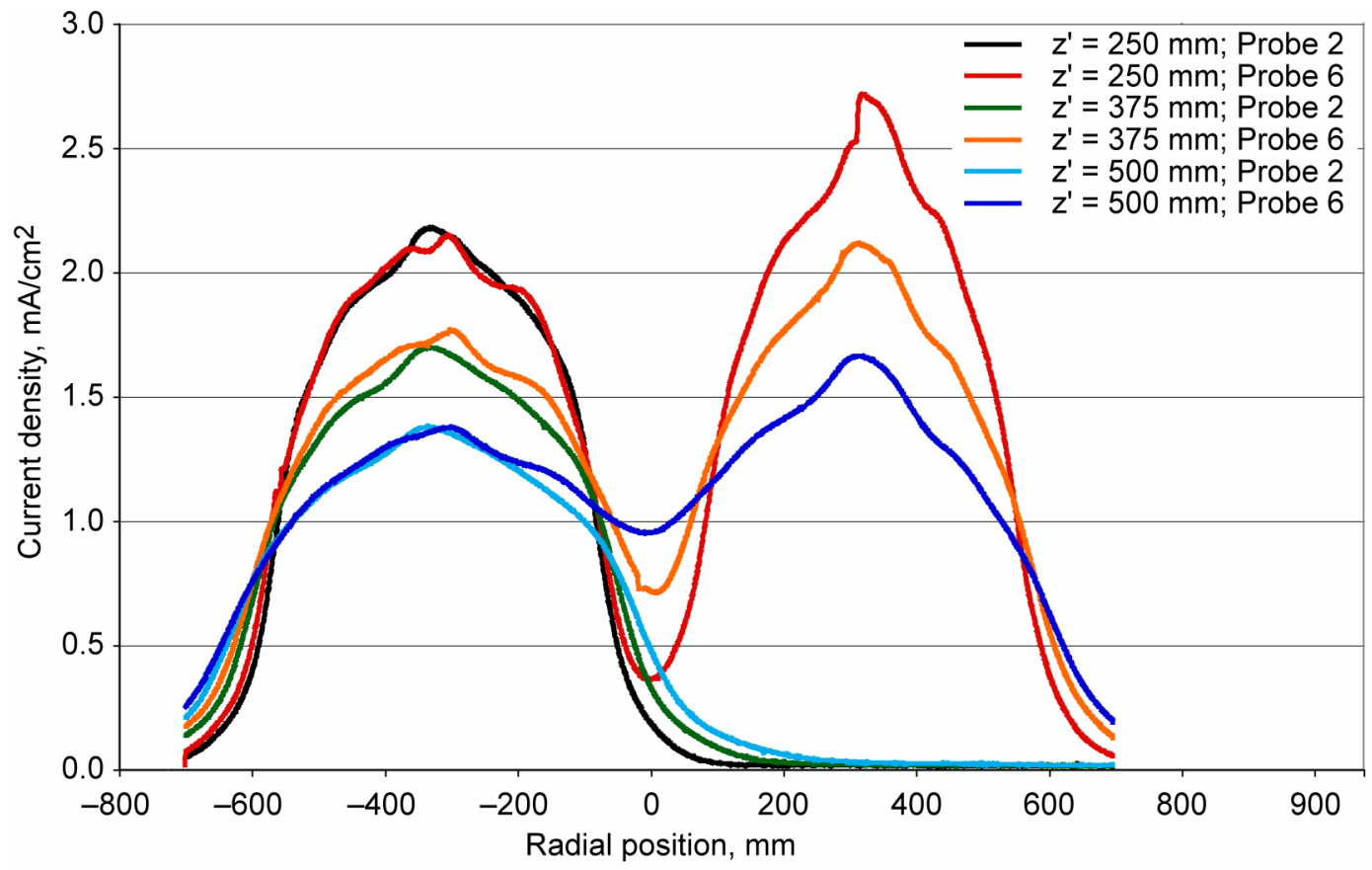

Figure 9.-Ion current density profiles during multiple thruster operation (EM1 + EM4 + EM5) at FP. 


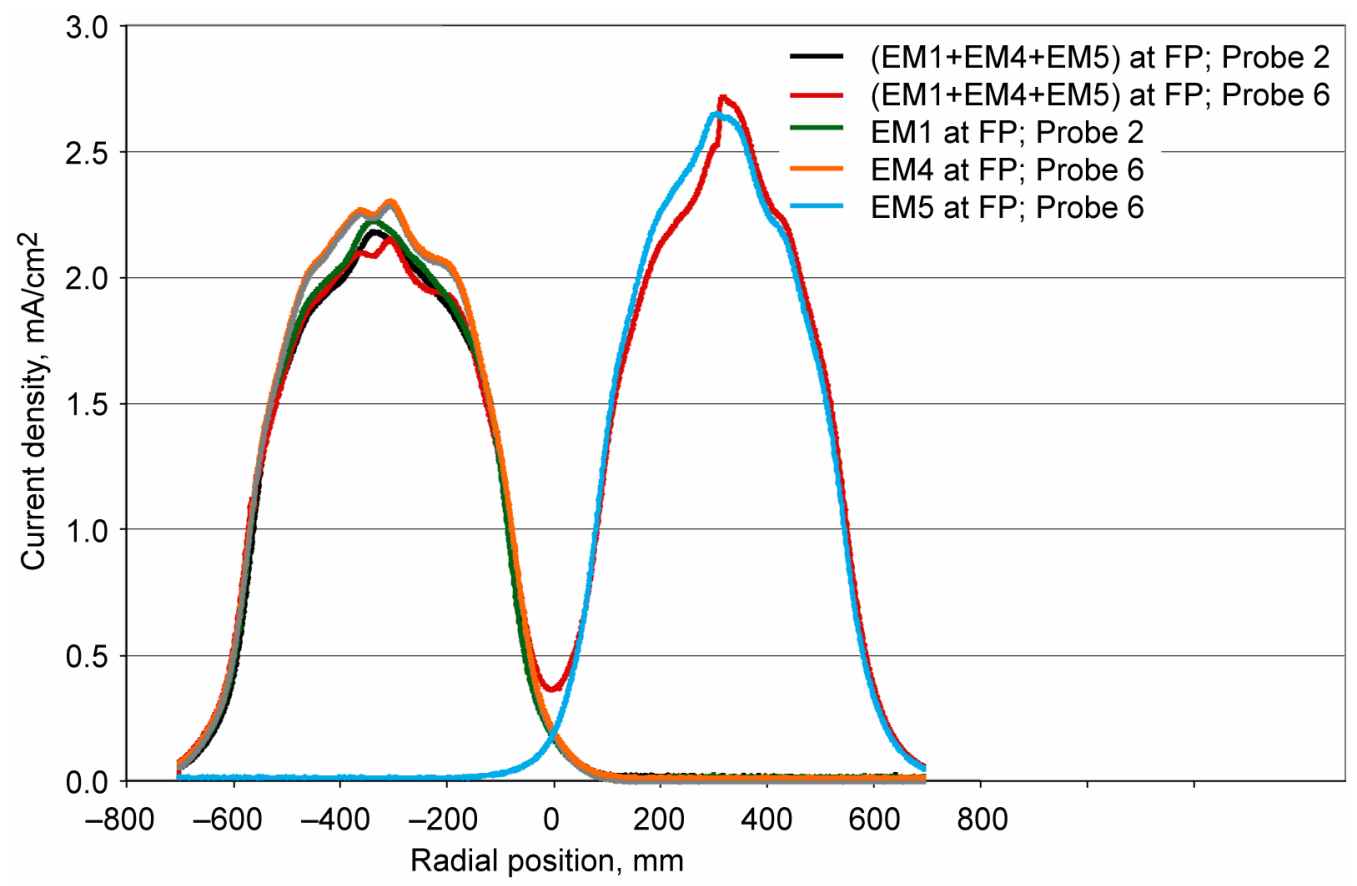

Figure 10.-Comparison of ion current density profiles for single engine operation to multiple engine operation.

operation were comparable. The profiles agreed well near the thruster centerlines, where the beams did not overlap. Near the array centerline $-75 \mathrm{~mm}<\mathrm{x}^{\prime}<75 \mathrm{~mm}$, the beam profile collected during multiple thruster operation indicated the beams had overlapped at this axial location. The beam profiles, in regions where beams intersected, did not match beam profiles collected during single engine operation, but could be matched by the superposition of the two individual beam profiles. In general overlay of single engine current density profiles onto multiple engine profiles indicated there was no significant difference in the beam profiles between single thruster operation and multiple thruster operation.

Additional analysis was conducted to gain insight into the behavior of the beam profiles in the regions where the diverging beams overlapped. Since the ion expansion in this region of the plume was collisionless, the beam profiles collected during multiple engine operation should be predicted by the superposition of individual ion thruster beams. To determine if regions of beam overlap was due to simple superposition, the profiles in the region of overlap were added. Figure 11 shows a comparison of beam profiles measured during multiple engine operation at $\mathrm{z}^{\prime}=250 \mathrm{~mm}$ and beam profiles calculated by adding those measured during single engine operation at the same axial distance. The resulting summation agreed well the primary beam profile near the thruster centerline as well as the array centerline. The results indicated that multi-thruster beams could be predicted from single thruster beam profiles by superimposing the beam profiles collected during single thruster operation. 


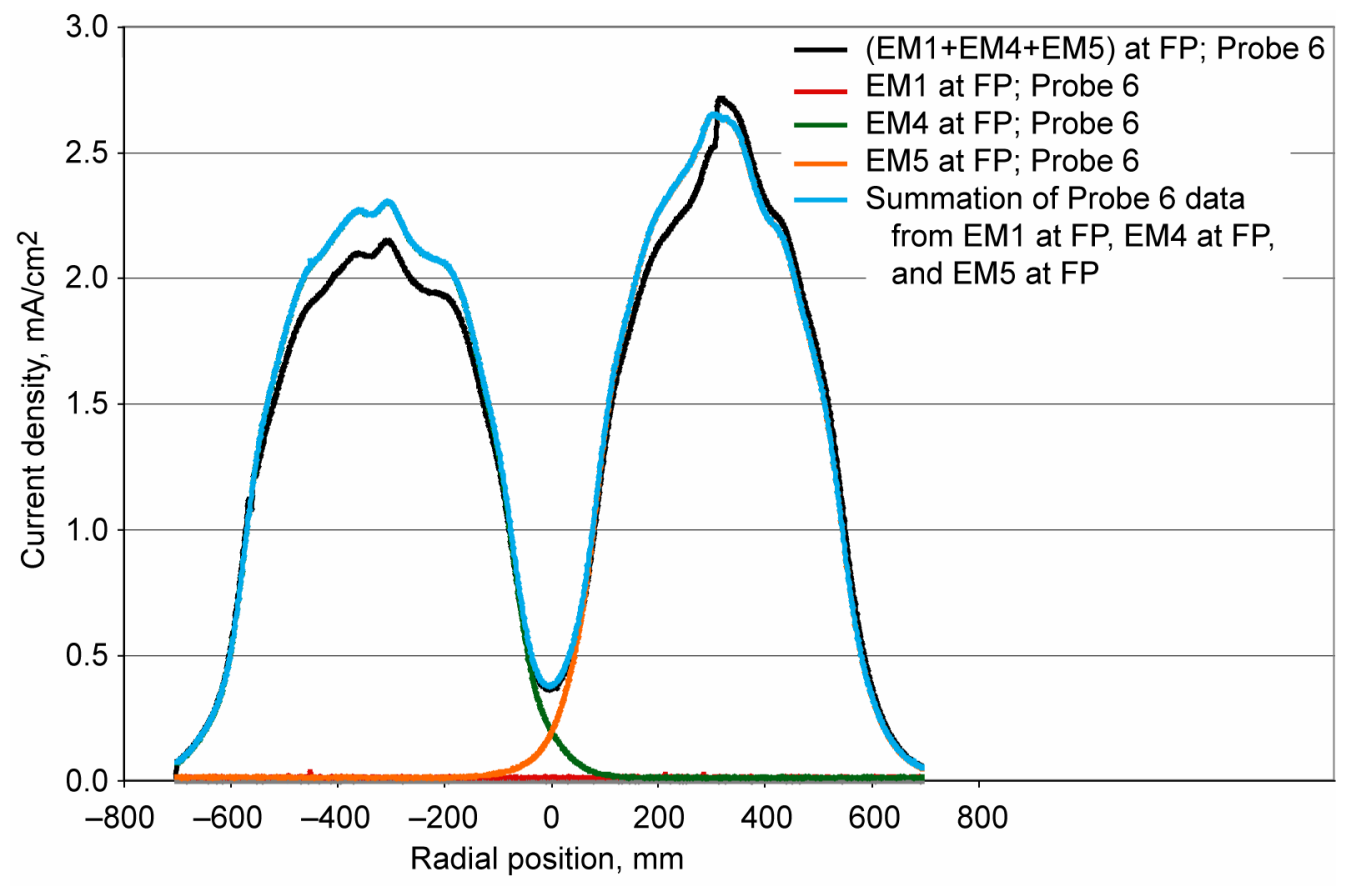

Figure 11.-Comparison of beam profiles measured during multiple engine operation, $(E M 1+E M 4+E M 5)$ at FP, to summation of beam profiles measured during single engine operation (EM1 at FP, EM4 at FP, and EM5 at FP).

\section{Multiple Thruster Operation - Off-axis Ion Energy Distribution}

The impact of the number of operating thrusters on the ion energy distribution was characterized by the off-axis RPA located at $45^{\circ}$ from the centerline of EM1. The off-axis beam ions were characterized during single thruster operation (EM1@FP), double thruster operation(EM1+EM5)@FP, (EM1+EM4)@FP, and triple thruster operation(EM1+EM4+EM5)@FP for this study. The results are shown in figure 12(a) to (b). In figure 12(a), the collected current is plotted as a function of the probe bias voltage. The normalized I-V curves compare well in all cases. The derivatives of the I-V curves, which indicate the ion energy distribution, are shown in figure 12(b). The peak ion energy was the same in all cases; $1830 \mathrm{eV}$, which compared well with the beam voltage of $1790 \mathrm{~V}$. The results indicated that there was no impact on the ion energy distribution due to the number of operating thrusters. Also the ion energy distribution was not significantly affected by the associated changes in background pressure due to the number of operating thrusters in this test configuration.

\section{E. Alternate Neutralizer Configurations}

Alternate neutralizer configurations were examined as part of this test program to evaluate these configurations as a system operational fault recovery mode, and as a performance-enhancing system architecture. Ion current density profiles were characterized for each neutralizer-thruster combination. In this report one alternate neutralizer configuration was selected as representative case for the general trends. The baseline configuration used for this investigation was the low power operation of both EM1 

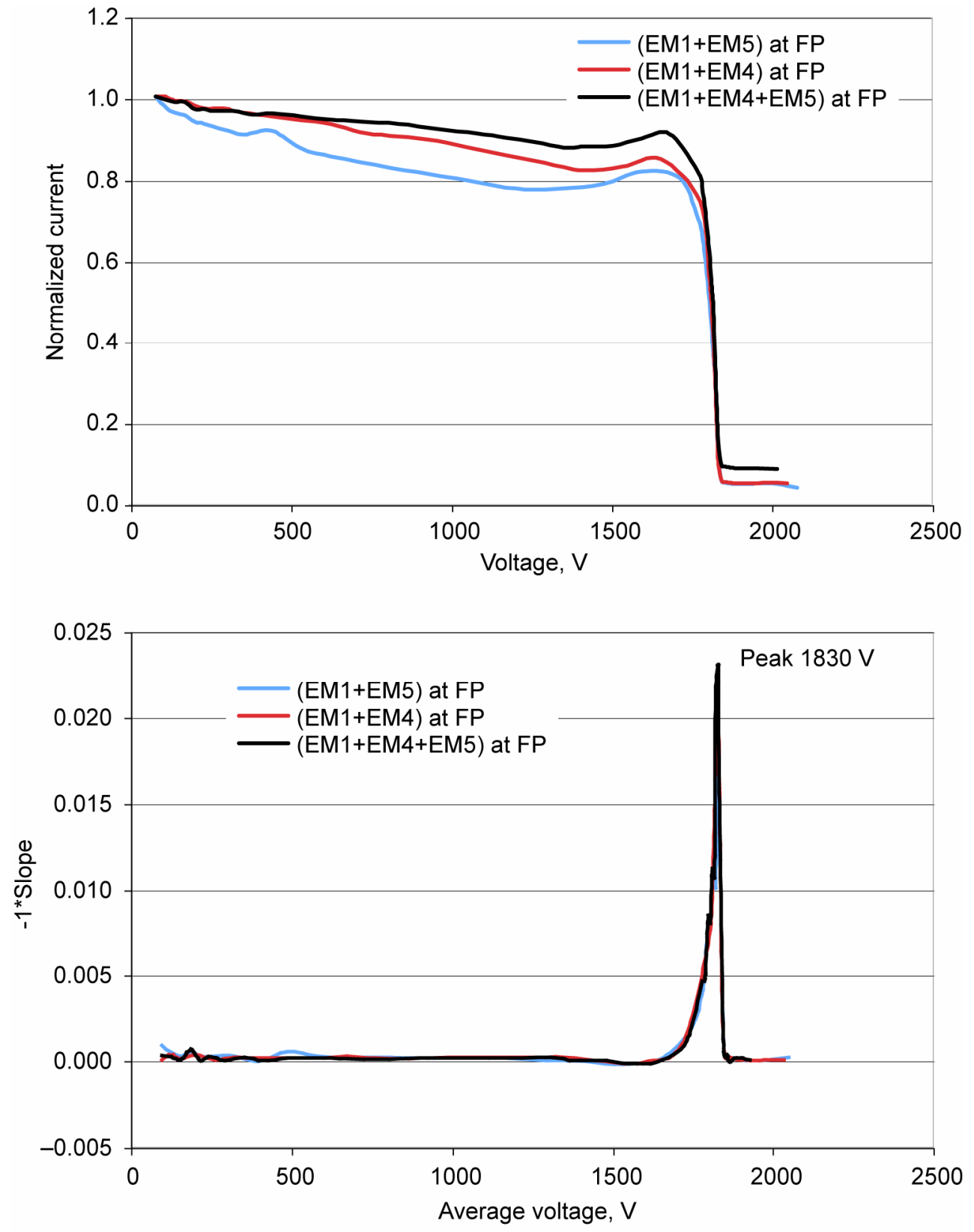

Figure 12.-(a) Normalized RPA collector current as a function of bias voltage for multiple thruster operation with EM1. (b) Ion energy distribution functions for multiple thruster operation with EM1. 

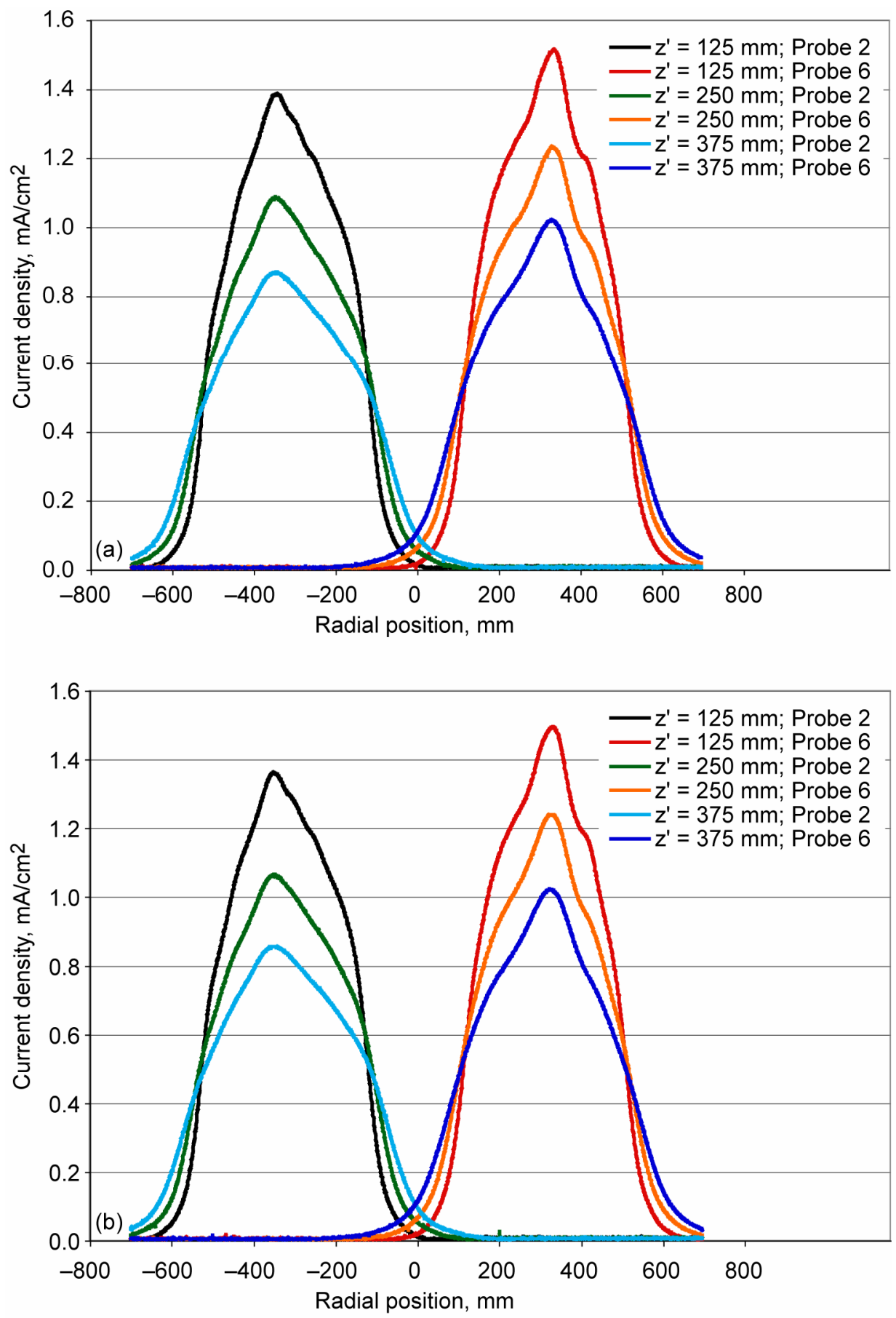

Figure 13.-(a) lon current density profiles collected with two neutralizers during (EM1+EM5) at LP operation. (b) Ion current density profiles collected with one neutralizer during (EM1+EM5) at LP operation.

and EM5 with both neutralizers operating at nominal conditions. Current density profiles were collected at three axial locations for nominal low power operation of EM1 and EM5 (with both neutralizers) and are shown in figure 13(a). Both the power and xenon flow rate to the neutralizer of EM5 were then turned off, leaving the neutralizer of EM1 as the sole operating neutralizer during the simultaneous operation of EM1 and EM5. The ion current density profiles were characterized at three axial locations for this 
configuration and are shown in figure 13(b). A comparison of the beam profiles collected for both cases showed no change in the beam profile between the two neutralizer-thruster configurations, which indicated that EM1 neutralizer effectively neutralized the beam plasma for distances on the order of $1 \mathrm{~m}$ without degrading thrust performance of either engine. This result was promising in that it highlighted multiple-thruster, single-neutralizer operation as a system operation fault recovery mode and/or a possible performance-enhancing system architecture as discussed in reference 9.

\section{E. Gimbal Articulation}

The impact of gimbal operations on thruster ion beam was examined to identify possible sympathetic processes which may be related to thruster gimbal angle. The test involved the simultaneous operation of EM1 and EM5 at FP, while EM1 was articulated over a full range of motion by a gimbal actuator. The array was first configured into its nominal orientation (with gimbal angles of $0^{\circ}$ on all thrusters). EM1 was then actively articulated in the radial direction (relative to the array center) and then the tangential direction (perpendicular to the radial direction) while operating. The thruster orientations, shown graphically in figure 14 , included; $12.4^{\circ}$ radially in, $10.2^{\circ}$ radially out, $11.3^{\circ}$ tangentially up, and $11.1^{\circ}$ tangentially down. Ion beam profiles were collected at each orientation (see Reference 6 for additional information about test setup).

Figure 15(a) shows current density profiles collected at an axial distance of $175 \mathrm{~mm}$ as EM1 was articulated radially. Figure 15(b) shows current density profiles collected at an axial distance of $175 \mathrm{~mm}$ as EM1 was articulated tangentially. The beam profile of EM5 did not change more than a few percent as EM1 was articulated in either the radial or tangential directions. The EM1 beam profiles shifted, as expected, as EM1 was articulated in both the radial and tangential directions. If the beam was perfectly symmetric and the probe was perfectly aligned, the peak current density of the beam profile would have decreased as the thruster was gimballed away from the $0^{\circ}$ position. However, azimuthal asymmetry in the beam peak current density near the thruster centerline has been observed in other ion thruster tests. As EM1 was articulated away from the $0^{\circ}$ position, a localized increase in the peak current density was observed. This trend was noted in two cases where EM1 was articulated $10.2^{\circ}$ radially outward and $11.3^{\circ}$ tangentially upward. This may have indicated that there was a localized spot of higher current density
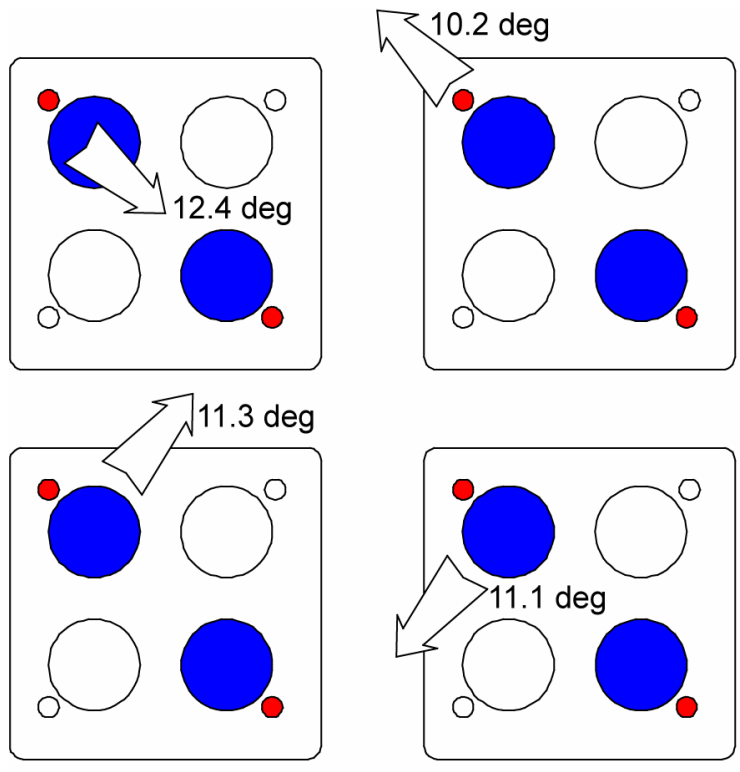

Figure 14.- Test configuration and gimbal range for gimballing test. 

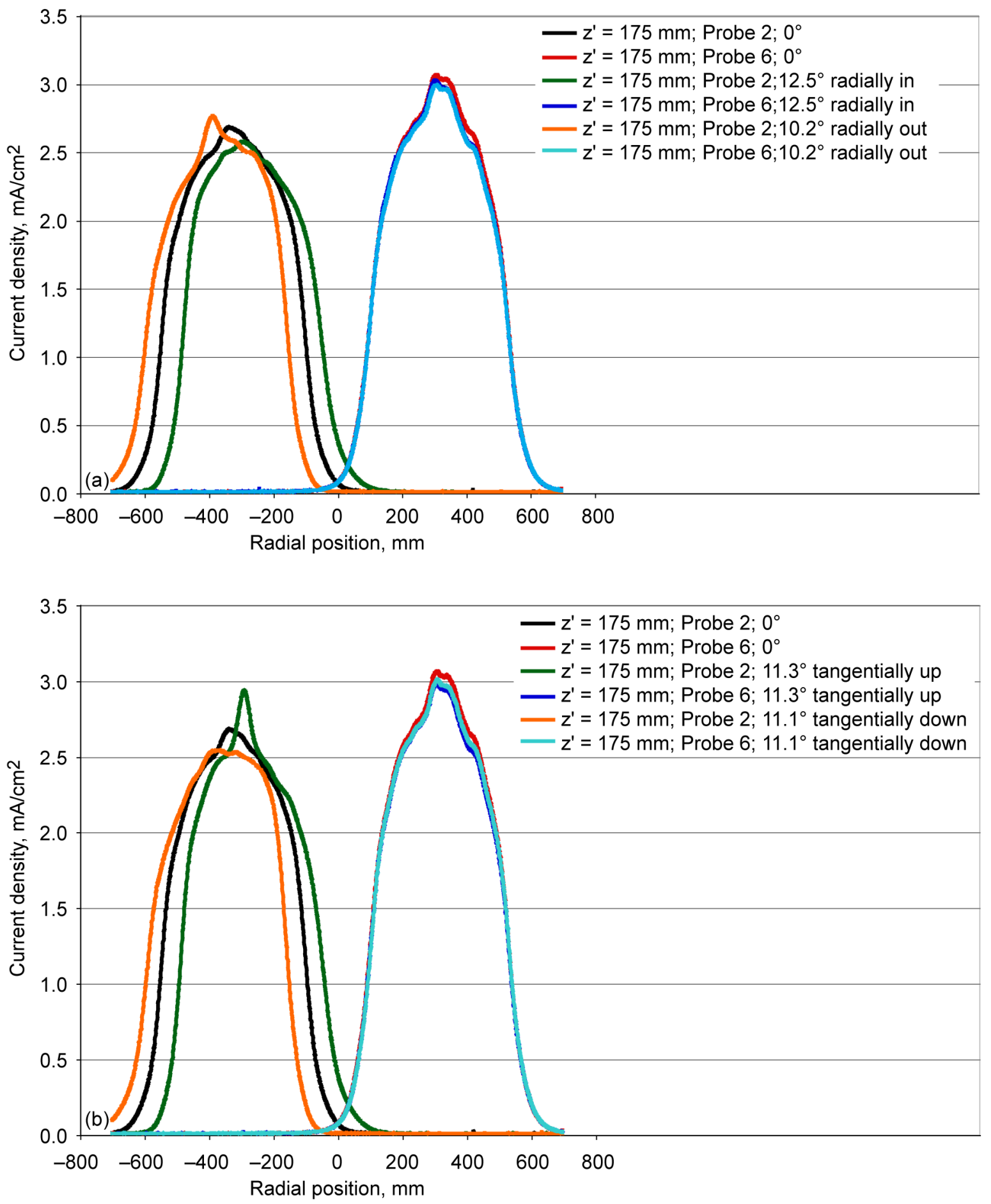

Figure 15.-(a) lon current density profiles collected at $z^{\prime}=175 \mathrm{~mm}$ as EM1 is gimballed radially. (b) lon current density profiles collected at $z^{\prime}=175 \mathrm{~mm}$ as EM1 is gimballed tangentially. 

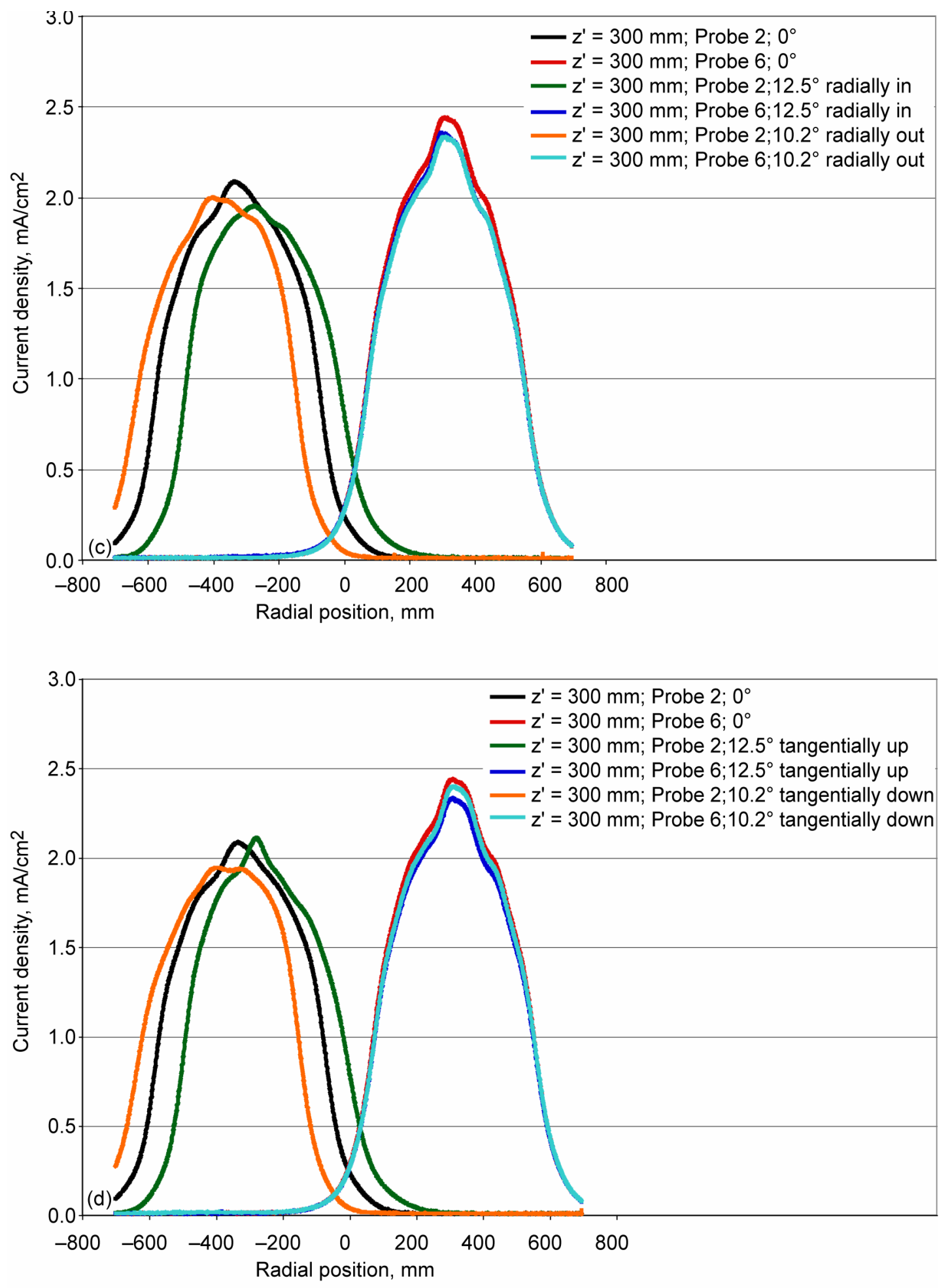

Figure 15.-(c) Ion current density profiles collected at $z^{\prime}=300 \mathrm{~mm}$ as EM1 is gimballed radially. (d) Ion current density profiles collected at $z^{\prime}=300 \mathrm{~mm}$ as EM1 is gimballed tangentially. 
below the plane of the thruster centerline of EM1 or perhaps a small probe misalignment. Figure 15(c) shows current density profiles at an axial distance of $300 \mathrm{~mm}$ as EM1 was articulated radially. Figure 15(d) shows current density profiles collected at an axial distance of $300 \mathrm{~mm}$ as EM1 was articulated tangentially. Azimuthal asymmetry was again noted when EM1 was articulated $10.2^{\circ}$ radially outward and $11.3^{\circ}$ tangentially upward, although the resulting variations in peak current density were lessened as axial distance increased. The EM1 beam profiles shifted radially as EM1 was articulated in both the radial and tangential directions. Again the beam profile for EM5 did not change more than a few percent as EM1 was articulated.

In general as the EM1 thruster was articulated its beam profile shifted radially as expected, whereas the beam profile of a stationary thruster (EM5) near the articulating thruster did not change. The results indicated that there were no beam-beam interactions occurring during the gimbal maneuvers, which was consistent with a collisionless beam expansion.

\section{Conclusions}

Three operational NEXT ion thrusters were installed in a cluster array at NASA GRC. A series of engineering demonstration tests were performed to evaluate the system performance impacts of operating various thruster configurations in an array. A suite of diagnostics was installed to investigate array impact on thruster performance and life, thermal interactions, and alternative system modes and architectures. To ascertain impact on thrust-generating ions, the ion current density profile and ion energy distribution of the ion beam were measured by Faraday probes and an off-axis retarding potential analyzer. The ion beam was characterized during single thruster operation, multiple thruster operation, various neutralizer configurations, and single-thruster gimbal articulation.

In general, overlay of single engine current density profiles onto multiple engine profiles indicated there was no significant difference in the beam profiles between single thruster operation and multiple thruster operation. The summation of beam profiles collected during single engine operation agreed well with measured multiple thruster profiles near the thruster centerline as well as at the array centerline. The results indicated that multi-thruster beams could be predicted from single thruster beam profiles by superimposing the beam profiles collected during single thruster operation. The results from the off-axis RPA clearly showed that high-energy ions are present at $45^{\circ}$ off the thruster axis and that the peak ion energy did not vary due to the number of operating thrusters. Also, the peak ion energy was not effected by the associated changes in background pressure due to the number of operating thrusters in this test configuration. A comparison of the beam profiles collected for alternate neutralizer configurations showed no change in the beam profile between the two neutralizer-thruster configurations examined. In general, as one thruster was articulated its beam profile shifted as expected, whereas the beam profile of a stationary thrusters near the articulating thruster did not change.

\section{References}

1. Frandina, M., Carpenter, C. Soulas, G, Snyder, A. and Patterson, M., "Status of the NEXT Ion Engine Life Test," AIAA-2005-4065, 41st Joint Propulsion Conference, Tucson, AZ, July 2005.

2. Todd, P., Wiseman, S., Matinelli, R. and Pinero, L., "Status of the NEXT 7-kW Power Processing Unit," AIAA-2005-3868, 41st Joint Propulsion Conference, Tucson, AZ, July 2005.

3. Hoskins, W., Polaha, J., Hobson, D., Soulas, G. Patterson, M., Sovey, J. and Talerico, L., "Overview of the NEXT Ion Propulsion System Program at Aerojet," AIAA-2005-3885, 41st Joint Propulsion Conference, Tucson, AZ, July 2005.

4. Monheiser, J., Aadland, R. and Wilson, A., "Development of a Ground Based Digital Control Interface Unit (DCIU) for the NEXT Propulsion System," AIAA-2004-4112, 40th Joint Propulsion Conference, Fort Lauderdale, FL, July 2004. 
5. Benson, S., Patterson, M., Vaughn, D., Wilson, A. and Wong, B., "NASA's Evolutionary Xenon Thruster (NEXT) Phase 2 Development Status," AIAA-2005-4070, 41 st Joint Propulsion Conference, Tucson, AZ, July 2005.

6. Patterson, M., Foster, J., McEwen, H., Pencil, E., Van Noord, J. and Herman, D., "NEXT MultiThruster Array Test-Engineering Demonstration," AIAA-2006-5180, 42nd Joint Propulsion Conference, Sacramento, CA, July 2006.

7. McEwen, H., Foster, J., Pencil, E., Patterson, M., Diaz, E. and Van Noord, J., "Characterization of Plasma Flux Incident on a Multi-Thruster Array," AIAA-2006-5183, 42nd Joint Propulsion Conference, Sacramento, CA, July 2006.

8. Foster, J., Patterson, M., Pencil, E., McEwen, H., Diaz, E. and Van Noord, J., "Plasma Characteristics Measured in the Plume of a NEXT Multi-Thruster Array," AIAA-2006-5184, 42nd Joint Propulsion Conference, Sacramento, CA, July 2006.

9. Foster, J., Pencil, E., McEwen, H. Patterson, M., Diaz, E. and Van Noord, J., "Neutralizer Plasma Coupling in a NEXT Multi-Thruster Array," AIAA-2006-5184, 42nd Joint Propulsion Conference, Sacramento, CA, July 2006.

10. Oberto, R., et al., “Advanced Projects Design Team, Titan Orbiter 2003-10,” Jet Propulsion Laboratory (JPL) Report ID \#658, 2003.

11. Kamhawi, H., Soulas, G., Patterson, M. and Frandina, M., "NEXT Ion Engine 2000 hour Wear Test Plume and Erosion Results," AIAA-2004-3792, 40th Joint Propulsion Conference, Fort Lauderdale, FL, July 2004.

12. Soulas, G., et al., "NEXT Ion Engine 2000 Hour Wear Test Results," AIAA-2004-3971, 40th Joint Propulsion Conference, Fort Lauderdale, FL, July 2004. 
Public reporting burden for this collection of information is estimated to average 1 hour per response, including the time for reviewing instructions, searching existing data sources, gathering and maintaining the data needed, and completing and reviewing the collection of information. Send comments regarding this burden estimate or any other aspect of this collection of information, including suggestions for reducing this burden, to Washington Headquarters Services, Directorate for Information Operations and Reports, 1215 Jefferson Davis Highway, Suite 1204, Arlington, VA 22202-4302, and to the Office of Management and Budget, Paperwork Reduction Project (0704-0188), Washington, DC 20503.

\begin{tabular}{|l|l|l|}
\hline 1. AGENCY USE ONLY (Leave blank) & $\begin{array}{c}\text { 2. REPORT DATE } \\
\text { November } 2006\end{array}$ & $\begin{array}{r}\text { 3. REPORT TYPE AND DATES COVERED } \\
\text { Technical Memorandum }\end{array}$ \\
\hline
\end{tabular}

4. TITLE AND SUBTITLE 5. FUNDING NUMBERS

Ion Beam Characterization of a NEXT Multi-Thruster Array Plume

6. AUTHOR(S)

WBS 346620.04.05.03.01

Eric J. Pencil, John E. Foster, Michael J. Patterson, Esther M. Diaz, Jonathan L. Van Noord, and Heather K. McEwen

7. PERFORMING ORGANIZATION NAME(S) AND ADDRESS(ES)

National Aeronautics and Space Administration

John H. Glenn Research Center at Lewis Field

Cleveland, Ohio 44135-3191

8. PERFORMING ORGANIZATION REPORT NUMBER

E-15700

9. SPONSORING/MONITORING AGENCY NAME(S) AND ADDRESS(ES)

National Aeronautics and Space Administration

Washington, DC 20546-0001

10. SPONSORING/MONITORING AGENCY REPORT NUMBER

NASA TM-2006-214423

AIAA-2006-5182

\section{SUPPLEMENTARY NOTES}

Prepared for the 42nd Joint Propulsion Conference and Exhibit cosponsored by the AIAA, ASME, SAE, and ASEE, Sacramento, California, July 9-12, 2006. Responsible person, Eric J. Pencil, organization code RPP, 216-433-7463.

12a. DISTRIBUTION/AVAILABILITY STATEMENT

12b. DISTRIBUTION CODE

Unclassified - Unlimited

Subject Category: 20

Available electronically at http://gltrs.grc.nasa.gov

This publication is available from the NASA Center for AeroSpace Information, 301-621-0390.

13. ABSTRACT (Maximum 200 words)

Three operational, engineering model, 7-kW ion thrusters and one instrumented, dormant thruster were installed in a cluster array in a large vacuum facility at NASA Glenn Research Center. A series of engineering demonstration tests were performed to evaluate the system performance impacts of operating various multiple-thruster configurations in an array. A suite of diagnostics was installed to investigate multiple-thruster operation impact on thruster performance and life, thermal interactions, and alternative system modes and architectures. The ion beam characterization included measuring ion current density profiles and ion energy distribution with Faraday probes and retarding potential analyzers, respectively. This report focuses on the ion beam characterization during single thruster operation, multiple thruster operation, various neutralizer configurations, and thruster gimbal articulation. Comparison of beam profiles collected during single and multiple thruster operation demonstrated the utility of superimposing single engine beam profiles to predict multi-thruster beam profiles. High energy ions were detected in the region $45^{\circ}$ off the thruster axis, independent of thruster power, number of operating thrusters, and facility background pressure, which indicated that the most probable ion energy was not effected by multiple-thruster operation. There were no significant changes to the beam profiles collected during alternate thruster-neutralizer configurations, therefore supporting the viability of alternative system configuration options. Articulation of one thruster shifted its beam profile, whereas the beam profile of a stationary thruster nearby did not change, indicating there were no beam interactions which was consistent with the behavior of a collisionless beam expansion.

14. SUBJECT TERMS

Electric propulsion; Ion thrusters; Multi-thruster arrays 15. NUMBER OF PAGES 26

\begin{tabular}{|c|c|c|}
\hline $\begin{array}{c}\text { 17. SECURITY CLASSIFICATION } \\
\text { OF REPORT } \\
\text { Unclassified }\end{array}$ & $\begin{array}{c}\text { 18. SECURITY CLASSIFICATION } \\
\text { OF THIS PAGE } \\
\text { Unclassified }\end{array}$ & $\begin{array}{c}\text { 19. SECURITY CLASSIFICATION } \\
\text { OF ABSTRACT } \\
\text { Unclassified }\end{array}$ \\
\hline
\end{tabular}



